\title{
Compound word effects differ in reading, on-line naming, and delayed naming tasks
}

\author{
ALBRECHT WERNER INHOFF, DEBORAH BRIIHL, and JILL SCHWARTZ \\ State University of New York, Binghamton, New York
}

\begin{abstract}
Bimorphemic compound words (e.g., blueberry), bimorphemic suffixed words (e.g., ceaseless), and monomorphemic controls (e.g., arthritis) were read in neutral sentence contexts in Experiment 1. The main result revealed longer first fixation durations on compound words than on control and suffixed words. Different effects emerged when naming tasks were used. An on-line naming task revealed substantially shorter naming latencies for compound words than for control and suffixed words. Naming latencies for compound and control words were equivalent in a delayed naming task. These results indicate that on-line naming latencies and word-viewing durations may yield diverging results. They also suggest that activation of constituent words of compound words occurs independently from the specification of conventional word meanings.
\end{abstract}

The results of a large number of word recognition tasks and participant populations have indicated that word stems (root morphemes) and inflexional suffixes are represented separately in the linguistic knowledge system (see Taft, 1985). For instance, root morphemes show robust effects of repetition priming, with larger priming effects when stems are repeated than when matched nonstems are repeated (Feldman, 1994; Feldman \& Bentin, 1994; Fowler, Napps, \& Feldman, 1985), and the frequency of root morphemes determines lexical decision times, with shorter decision latencies for high-frequency roots (Beauvillain \& Segui, 1989). Neuropsychological investigations also suggest representation of root morphemes of suffixed words. Coslett and Saffran's (1989) examination of 4 patients with left cerebral hemisphere lesions showed that these patients often correctly named the root of a suffixed word but not its suffix. The patients also showed a deficit in root-affix distinctions in a lexical decision task where incorrectly suffixed words (e.g., elephanting) and correctly suffixed words (e.g., augmenting), could not be discriminated. However, these results are not unchallenged. Bergman, Hudson, and Eling (1988, Experiments 2 and 4) compared lexical decision times on bimorphemic, root-plus-suffix words with monomorphemic, pseudosuffixed words. The results revealed virtually identical response times for the two types of words.

Meaning conveying morpheme constituents may also contribute to word recognition when compound words are recognized, though discrepancies of results across studies are also apparent for this type of words. Using a lexical de-

Research on this project was supported by NIMH Grant 50387 and by the Center of Cognitive and Psycholinguistic Studies. The authors thank Cynthia Connine and two reviewers for their helpful comments on an earlier version of the manuscript. Correspondence should be addressed to A. W. Inhoff, Department of Psychology, State University of New York at Binghamton, Binghamton, NY 13902-6000 (e-mail: inhoff@bingvmb. cc.binghamton.edu) cision task, Taft and Forster (1976) obtained longer nonword decision latencies when the beginning letter sequence formed a word (morpheme) than when it formed a pseudoword. No corresponding effect was evident for ending letter sequences. Lima and Pollatsek (1983) and Andrews (1986) also obtained morpheme-related effects in the lexical decision task; however, in contrast to the results of Taft and Forster (1976), their results showed that beginning and ending constituent morphemes were effective. In Lima and Pollatsek's Experiment 3, classification of wordword nonwords (e.g., shipsnack) was slower and more error prone than was classification of word-nonword nonwords (e.g., sunkib), presumably because beginning and ending morphemes were used to find lexical entries.

The morphological composition of compound words also appears to determine the perception of constituents, such as the color of a constituent letter in Prinzmetal's neoncolor illusion studies (Prinzmetal, 1990; Prinzmetal, Hoffman, \& Vest, 1991). On a typical trial, a compound (e.g., anthill) or monomorphemic, bisyllabic control word (e.g., pretzel) was shown, with the center letter of the compound ( $h$ in the example) being adjacent to a morphemic boundary and the center letter of the monomorphemic control ( $t$ in the example) being adjacent to a corresponding syllable boundary. Letters preceding and following each center letter were shown in different colors. The color of the center letter itself was ambiguous and consisted of an overlay of beginning and ending letter colors. Under these viewing conditions, the perception of the ambiguous center letter was systematically biased, in that it took on the color of the encompassing morpheme unit. No corresponding bias was evident for monomorphemic control words.

Perhaps even more dramatic are effects of morphemic structure on the loss of letter visibility in a retinal stabilization study (Inhoff \& Topolski, 1994a). In the critical experiment, a visible compound or pseudocompound word was continuously projected at the same retinal location until it faded from vision. Occasional loss of center-letter visibil- 
ity occurred when the letter was adjacent to a morpheme boundary (e.g., loss of $w$ or $b$ visibility when cowboy was stabilized) but not when it was adjacent to a pseudomorpheme boundary (e.g., no loss of $p$ or $k$ visibility when napkin was stabilized).

Other findings suggest a more limited role of morpheme constituents during word recognition. Sandra (1990) obtained morpheme-related effects when compound words contained semantically transparent constituents (e.g., teaspoon) but not when they contained opaque constituents (e.g., buttercup). Specifically, primes consisting of the beginning or ending constituent facilitated subsequent lexical decisions when morphologically transparent compound words were classified but not when opaque compounds were classified. Even more problematic is the lack of morphemerelated effects during normal sentence reading (Inhoff, $1987,1989 a$ ), where word-viewing durations on six-letter compound words were virtually identical to word-viewing durations on length- and frequency-matched pseudocompound words. Use of lexical information prior to the fixation of a word during sentence reading also does not appear to involve the extraction of morphological information (Inhoff, 1989a), since parafoveal previews of morphemes (e.g., cow) and of pseudomorphemes (e.g., nap), were equally useful when the full word forms (cowboy and napkin, respectively) were subsequently fixated.

The majority of studies examining the use of morphological structure in the word recognition process used the lexical decision task. Though the task may be sensitive to some lexical processes, it also appears to be subject to postrecognition confounds (see Balota \& Chumbley, 1984; Seidenberg, Waters, Sanders, \& Langer, 1984). It is also unclear whether effects of morphology on color classification and on the loss of visibility during retinal stabilization reflected the use of morphological knowledge during the recognition process. Changes in the perception of a letter's color or its presence could have occurred after the word had been recognized. The present study pursued two main goals: (1) to determine whether morphology was used in the word recognition process and (2) to determine whether morphologyrelated effects are a function of task demands.

\section{Task Demands}

Processes that control word identification during normal reading may differ from perceptual and linguistic processes that control word identification when words are presented in isolation, as occurs in most categorization and naming tasks. During reading, each word is part of an extended visuospatial pattern, and readers generally obtain useful information from a to-be-identified word in the parafovea, with word recognition often being distributed across several fixations (see Carr \& Pollatsek, 1985, and Rayner \& Pollatsek, 1987, for reviews).

Classification and naming tasks impose response demands that are not present during normal reading. Specifically, participants are required to execute an overt response to visual stimuli. These overt responses, generally in the form of manually signaled classifications, oral stimulus naming, or other types of identification attempts, are rel- atively slow and could be subject to a variety of postrecognition distortions. As noted before, postrecognition effects on lexical decision latencies have been noted in the literature (Balota \& Chumbley, 1984; Seidenberg et al., 1984). Postrecognition processes may also account for effects of morphemic structure on perceptual illusions (Prinzmetal, 1990; Prinzmetal et al., 1991) and on the loss of letter visibility (Inhoff \& Topolski, 1994a).

The naming task appears less subject to postrecognition effects and has become the primary tool in the study of prelexical and lexical processes (Monsell, Doyle, \& Haggard, 1989; Seidenberg et al., 1984). The task is devoid of decision processes, and responses may be initiated before the full stimulus has been identified (Monsell et al., 1989). Results of the naming task appear to be highly consistent with results from reading studies, in which nonobtrusive word-viewing durations were used to assess linguistic processes (Pollatsek, Lesch, Morris, \& Rayner, 1992; see also Rayner \& Pollatsek, 1989, chap. 4). This was stressed by Pollatsek et al. (1992, p. 154), who stated that "virtually every prior effect from the naming task has generalized to the reading of text," and was confirmed by their results, which revealed corresponding effects of phonological coding on word-viewing durations during reading and online naming latencies.

Yet, some caution is warranted in the use of the naming task, since it may not be immune from task demands. Several studies have shown that naming latencies are affected by the composition of the stimulus list (Baluch \& Besner, 1991; Monsell, Patterson, Graham, Hughes, \& Milroy, 1992; Paap \& Noel, 1991), indicating that naming latencies can be affected by identification strategies. Other studies have shown that naming latencies may reflect speech programming demands. For instance, the phonological status of a to-be-named word (Inhoff \& Topolski, 1994b) and its frequency of occurrence (Balota \& Chumbley, 1985; McRae, Jared, \& Seidenberg, 1990) affected word-naming latencies, even after the word was fully identified prior to the presentation of the naming signal.

On the one hand, task specific effects of morphology pose a theoretical dilemma, since models of word recognition, in so far as they are based on task-specific evidence (Dell, 1986; Taft \& Forster, 1976), could be based on epiphenomena. On the other hand, discrepancies between tasks could be used to define the nature of morphology-related effects, if the source of discrepancies was specified. For instance, response latencies could be a function of a word's morphological complexity in Task A but not in Task B. If Task A was primarily sensitive to the accessing of lexical knowledge and Task B was sensitive to postlexical use of knowledge, then it could be concluded that morphology was used in the accessing of lexical knowledge.

The present study used three types of tasks, two of which-sentence reading and on-line naming-appear to be sensitive to word recognition demands (Pollatsek et al., 1992; Rayner \& Duffy, 1986; Rayner \& Pollatsek, 1989). A delayed naming task was used to measure postrecognition speech-planning demands (Balota \& Chumbley, 1985; Inhoff \& Topolski, 1994b; McRae et al., 1990). Relatively 
long nine-letter compound, suffixed, and monomorphemic words were selected to increase experimental power and the likelihood that morphemic structure would affect word-viewing durations during reading. Target words were embedded in neutral sentence contexts in Experiment 1 (reading tasks) and shown in isolation in Experiment 2 (on-line and delayed naming tasks).

If lexically represented elements of complex words contribute to word recognition, then compound words, with two lexically represented constituents, may be recognized more effectively than suffixed and control words. Suffixed words, with meaning conveying root morphemes, and full word forms may be recognized more effectively than nondecomposable, monomorphemic control words. No corresponding effects should occur in the delayed naming task, if morphology was used during the recognition process. If, however, morphological structure was used in the postlexical specification of a speech program, then on-line and delayed naming tasks should yield equivalent effects of morphology, and the results of both naming tasks could differ from the results of the reading task.

\section{EXPERIMENT 1 Target Viewing During Reading}

\section{Method}

Subjects. Twenty-five undergraduate students at the State University of New York at Binghamton were paid or received course credit for their participation in the experiment. All subjects had uncorrected vision and were naive about the purpose of the experiment.

Materials. Forty-five nine-letter target nouns were selected. One third of these targets consisted of bimorphemic compound words, one third consisted of bimorphemic suffixed words, and one third consisted of monomorphemic control words. Monomorphemic control words did not contain any morphemic subword units, though several words contained pseudomorphemic beginnings (e.g., art of arthritis, or cat of cathedral ). Most compound words contained fourand five-letter word constituents, but some compounds contained shorter morphemes. Suffixed words consisted of either a five-letter root followed by a four-letter suffix or a six-letter root followed by a three-letter suffix. Bigram transition frequencies may signal morphemic boundaries transitions between intraword units (Seidenberg, 1987), but it appears unlikely that bigram transitions account for all morphology-related effects (Rapp, 1992). Examination of bigram frequencies at the morphological boundary of compound and suffixed words revealed higher mean transition frequencies for suffixed words $(14,347)$ than for compound words $(7,192)$ (Solso \& Juel, 1980). This difference was due to the inclusion of the high-frequency bigram th of one suffixed word (sainthood). Median frequencies showed the opposite bias, with lower bigram frequencies for suffixed words (691) than for compound words $(1,099)$, indicating that letter transition frequencies did not discriminate between the two word types.

Since word-viewing durations are a function of the fixated word's frequency of occurrence (e.g., Inhoff \& Rayner, 1986; Just \& Carpenter, 1980; Rayner \& Duffy, 1986), the three word types were matched on this variable, with mean frequencies counts of $2(S D=2)$, $2(S D=2)$, and $5(S D=4)$ per million (Kučera \& Francis, 1967) for compound, suffixed, and control words, respectively. The initial morpheme of compound and suffixed words was considerably more familiar than the frequency of the full word, with word frequency counts of 350 and 71 per million, respectively. All suffixed words and most compound words contained two syllables, but the majority of monomorphemic words contained three syllables. Control words were also more likely to contain a phonologically irregular word segment at the word ending. Results of prior studies suggested that syllable structure should not affect viewing durations in a standard reading task (Gielen, Brysbaert, \& Dhondt, 1991) and that phonological irregularities at word endings do not affect the ease of word recognition (Tousman \& Inhoff, 1992). A full listing of the three types of target words is shown in the Appendix.

Each target was embedded in a semantically neutral, congruent sentence context, and each target was preceded by an open-class content word with at least four letter constituents. Care was taken to ensure that target-preceding context was equally compatible with the three types of targets. This was confirmed in a supplementary rating study in which sentence foils, up to and including the target, were printed on a sheet of paper, with each sentence fragment being followed by a rating task. Ten subjects, none of whom participated in the reading study, rated the targets in their respective sentence fragments on contextual predictability. A scale from 1 to 7 was used, with 1 indicating a very poor fit and 7 indicating a very good fit. In this rating task, 10 additional filler fragments were included with highconstraint targets (e.g., The doctor meet the nurse [with nurse being the target]) and 10 were included with low-constraint targets (e.g., The flying eggshell [with eggshell being the target]) in order to make the rating task more meaningful for the participating students. The results of this norming study indicated that the experimental target words were equally constrained by prior context, with ratings of $5,4.9$, and 4.9 for compound, suffixed, and control words, respectively.

All sentences occupied a single line of text. They contained 6-10 words with a maximum of 75 character spaces, including interword blanks. Targets never occupied the first two word positions of a sentence or the sentence-final location.

Apparatus. All participants were tested in a sound-insulated, dimly illuminated room. A $60-\mathrm{Hz}$ noninterlaced VGA monitor was used to display text $(640 \times 480$ pixels $)$ that was shown in light green on a black background. The distance between the readers' eyes and the monitor was set at $70 \mathrm{~cm}$; at this viewing distance, each letter of text subtended approximately $0.33^{\circ}$ of visual angle.

Eye movements were recorded via a fifth-generation dual-Purkinje SRI eye-tracking system. Viewing was binocular, but eye movements were recorded from the right eye only. The system has a visual resolution of $10^{\prime}$ of arc, and its output was linear over the vertical and horizontal range of the visual display. Analog input from the eye tracker was digitized via a Data Translation 2801-A A-to-D converter housed in a personal computer. The computer controlled the visual display and stored horizontal and vertical fixation coordinates every $2 \mathrm{msec}$.

Procedure. The participants were tested individually. When a participant arrived in the laboratory, a bite bar was prepared that served to reduce head movements during the experiment. A twodimensional calibration of the eye-tracking system began the experiment. During calibration, the reader was requested to fixate four monitor positions (left top, right top, left bottom, right bottom) as they sequentially appeared on the screen and to manually depress a mouse button when the indicated location was accurately fixated. Buttonpressing resulted in the sampling of horizontal and vertical fixation location values for $150 \mathrm{msec}$. The $x / y \mathrm{~A} / \mathrm{D}$ converter values were then mapped onto the corresponding CRT locations. After calibration, five character-size squares were illuminated, one near each of the four monitor corners and one in the center of the screen. The reader's fixation location was indicated on the screen via a charactersize cursor grid that moved in synchrony with the eyes. The reader was asked to fixate each of the five illuminated locations and was reminded that the task was not to move the cursor onto the illuminated positions but to merely look at each position. The calibration was considered successful when the computer-generated eye position deviated by no more than one character space from each of the five calibration check positions.

After successful calibration, the reader was asked to fixate a onecharacter size marker at the left side of the screen and to depress a button to display a line of text. Buttonpressing replaced the fixation 
marker with a sentence and started the recording of eye positions. After sentence reading was completed, the reader was asked to manually press another button, which terminated the recording of eye movements for the trial, erased the visible sentence, and displayed another left-side fixation marker to check eye-tracking accuracy. The reader was asked to look at the fixation marker and to initiate the presentation of the next sentence, when eye tracking was accurate, and to initiate another calibration routine, when eye tracking was inaccurate. Sentence reading for meaning was encouraged, and the participants were occasionally asked to repeat or paraphrase the most recently read sentence. All sentences were reported correctly.

Design and data analysis. One list of target-containing sentences was constructed in which the ordering of word types was randomized. The list also contained 120 filler sentences, none of which contained a nine-letter compound, suffixed, or monomorphemic word. A target word was considered fixated when the point of fixation fell on one of its constituent letters or the blank space preceding it. Following Inhoff (1984), a large number of psycholinguistic studies have discriminated two measures of word processing: firstfixation durations and gaze durations. First-fixation durations were defined as the duration of the initial fixation on target words; gaze durations consisted of the cumulated target-viewing time prior to the fixation of another word. Instances in which the first fixation during sentence reading fell on the target word and instances in which the first target fixation followed a regression back to the target-each occurring on less than $1 \%$ of the trials--were excluded from analysis. A small number of targets were skipped (less than $4 \%$ ), and no first-fixation and gaze data were obtained in these instances.

First-fixation durations and gaze durations on target words were analyzed as a function of word type (compound, suffixed, control word). Error variance was computed across participants $(F 1)$ and items $(F 2)$. Supplementary analyses were also applied to interword saccade size to target words, intratarget-fixation locations, and targetrefixation frequencies.

\section{Results}

Gaze durations were similar across word types, amounting to 405,394 , and $408 \mathrm{msec}$ for compound, suffixed, and monomorphemic targets, respectively $(F 1$ and $F 2<1)$. First-fixation durations, however, were longer when compound words were fixated $(280 \mathrm{msec})$ than when suffixed and control words were fixated (260 and $252 \mathrm{msec}$, respectively) $\left[F 1(2,48)=14.10, M S_{\mathrm{e}}=374, p<.001\right.$; $\left.F 2(2,28)=4.75, M S_{\mathrm{e}}=724, p<.025\right]$. This was confirmed by paired comparisons, which showed that firstfixation durations on compound words were longer than first-fixation durations on suffixed words $[t 1(24)=4.2$; $t 2(14)=2.48]$ and on monomorphemic words $[t 1(24)=$ $4.64 ; t 2(14)=2.49$ ] (all $p s<.05)$. The 8-msec difference between suffixed and monomorphemic words was not reliable $[t(24)=1.6, S E=5.5, p>.12, t 2<1]$.

Lexical information is distributed differently in the three types of words. The meaning of a suffixed word is defined by its beginning; the meaning of a compound word, in contrast, is defined by its ending. Initial fixations near the word beginning could have been more useful than fixations near the ending when suffixed words were read, but fixations near the word ending could have been more useful when compound words were read. Subanalyses of first-fixation durations and gaze durations were conducted to examine this possibility.
Figure 1 shows relative frequencies with which each letter position, including the space preceding the target, was initially fixated.

Confirming earlier reports (Inhoff, 1989b; McConkie, Kerr, Reddix, \& Zola, 1988; O'Regan, 1990; Rayner, 1979), center letters were the most likely-and ending letters the least likely-recipients of a fixation. Two considerations suggested a combining of center and ending fixations: (1) Ending-letter fixations did not occur with sufficient frequency to permit a meaningful analysis on their own, and (2) target refixations (also shown in Figure 1) occurred more frequently when target-initial positions $(0-3)$ were fixated than when either a center or an ending position was fixated. At the extremes, more than $90 \%$ of Position 0 (blank space) fixations-but less than $20 \%$ of Position 9 fixations-were followed by an intratarget refixation.

Consequently, we discriminated two groups of target fixations: One group encompassing (nonoptimal) beginning locations ( $0-3)$, and a second group encompassing (more optimal) center/ending locations (4-9). First-fixation durations and gaze durations, as a function of word type and initial landing site, are shown in Table 1.

An analysis of variance (ANOVA) with the factors fixation location (2) and word type (3) showed a main effect of word type in the first-fixation durations $[F 1(2,48)=$ $\left.5.95, M S_{\mathrm{e}}=639, p<.005\right] .{ }^{1}$ However, the anticipated interaction of word type and initial fixation location was completely absent $(F \geq 1)$. Gaze durations showed no reliable main effect $(F 1<1)$, and the interaction of word type and fixation location was negligible $(F 1<1) .^{2}$

Supplementary analyses. Morphological structure also determined the location of the initial fixation on target words. The eyes' landing location was slightly closer to the target center when compound words were fixated (a mean letter fixation position of 4.4 ) than when suffixed and mono-

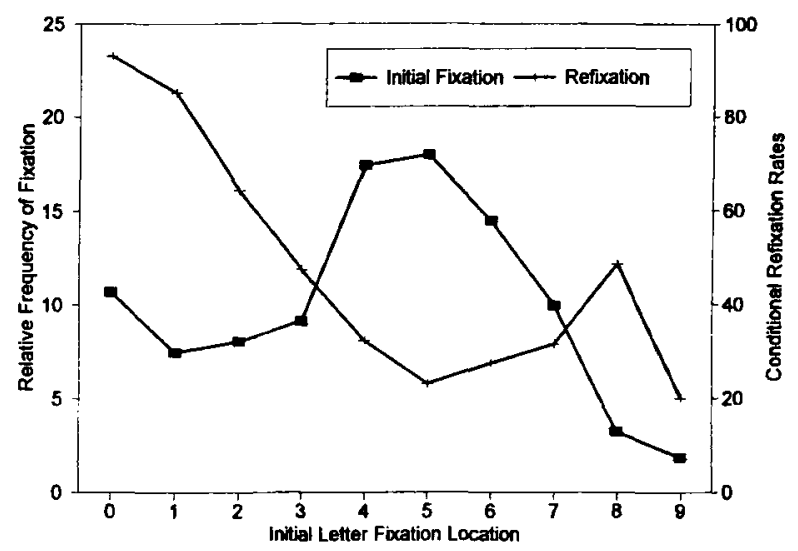

Figure 1. Fixation locations on target words. Relative frequencies with which target Positions 0 (the blank space preceding the target) to 9 were fixated are indexed on the primary $y$-axis. Refixation rates for each of the 10 target positions are indexed on the secondary $y$-axis. To determine refixation rates, the frequency with which a character position was refixated was divided by frequency with which it received an initial fixation. 
Table 1

Target First-Fixation Durations and Gaze Durations as a Function of Word Type and the Location of the First Target Fixation

\begin{tabular}{|c|c|c|c|c|c|}
\hline \multirow[b]{3}{*}{ Word Type } & \multicolumn{5}{|c|}{ Fixation Position } \\
\hline & \multicolumn{2}{|c|}{ Beginning } & \multicolumn{2}{|c|}{ Center/Ending } & \multirow[b]{2}{*}{$M$} \\
\hline & Duration & $S D$ & Duration & $S D$ & \\
\hline \multicolumn{6}{|c|}{ First-Fixation Durations } \\
\hline Compound & 241 & 44 & 293 & 46 & 267 \\
\hline Suffixed & 237 & 33 & 275 & 53 & 256 \\
\hline Monomorphemic & 223 & 33 & 277 & 48 & 250 \\
\hline \multicolumn{6}{|c|}{ Gaze Durations } \\
\hline Compound & 477 & 131 & 383 & 92 & 430 \\
\hline Suffixed & 467 & 135 & 352 & 100 & 410 \\
\hline Monomorphemic & 462 & 121 & 343 & 83 & 402 \\
\hline
\end{tabular}

Note-Values are given in milliseconds. The mean across fixation positions may not match the overall word-type mean due to the partitioning of data. $S D$, standard deviation. $M$, mean.

morphemic targets were fixated (Letter Positions 3.9 and 3.7 , respectively) $\left[F 1(2,48)=5.02, M S_{\mathrm{e}}=0.6, p<.01\right.$; $\left.F 2(2,28)=3.21, M S_{\mathrm{e}}=0.6, p<.056\right]$. Examination of the interword saccade size to target words indicated that the small, but robust, differences in fixation location were due to larger saccades to compound words $(9.5$ character spaces) than to suffixed and monomorphemic words $(8.8$ and 8.4 character spaces, respectively) $[F 1(2,48)=11.26$, $M S_{\mathrm{e}}=0.8, p<.001 ; F 2(2,28)=5.08, M S_{\mathrm{e}}=1.1, p<$ $.025]$. The small fixation location and interword saccade size effects did not affect intratarget refixations, with a mean refixation probability of .4 for all three target types $(F 1$ and $F 2<1){ }^{3}$

\section{Discussion}

First-fixation durations were longer when compound words were read than when suffixed and control words were read, irrespective of the location of the initial target fixation, though the effect was transient and no longer robust when gaze durations were analyzed. Increases in the first-fixation durations of fixated words are generally attributed to difficulties in word recognition, even when corresponding effects may no longer be evident in gaze durations (Lima \& Inhoff, 1985; Pollatsek et al., 1992). According to this view, the initial phase of word recognition is relatively difficult when compound words are encountered.

Yet, supplementary analyses also indicated that longer first-fixation durations on compound words were preceded by slightly larger saccades toward these words, resulting in a rightward shift of fixation locations toward the compound word center. Perhaps readers sought more lexical information when a more central word location was fixated, accounting for the increase in first-fixation durations. This would agree with O'Regan's (1990) view, according to which readers seek more linguistic information when a word's optimal viewing position is fixated than when a less optimal position is fixated.

Several considerations disagree, however, with this account. First, differences in intraword-fixation location were quite small, amounting to less than one character space. Second, optimal viewing position (OVP) effects in the recognition of single words may not generalize to the recognition of words in continuous text. When isolated words are recognized, each character-size deviation from the OVP may impose a recognition penalty of $20 \mathrm{msec}$ (O'Regan, 1990). However, a considerably less dramatic OVP effect emerges during reading. In this task, fixation positions at or near the very beginning and ending of long words are more likely to result in intraword refixations than are fixations near the word center (McConkie et al., 1988; Vitu, O'Regan, Inhoff, \& Topolski, 1995). All other fixation positions near the word center appear to be equally effective. Third, subanalyses of first-fixation durations, which took the location of the first intraword fixation into account, indicated that compound words received relatively long first-fixation durations, irrespective of the position of the initial target fixation. These considerations suggest that fixation-location differences did not determine the ease of encoding and that they cannot account for the increase in first-fixation durations on compound words. This conclusion is also congruent with the intraword-refixation data, which showed equivalent frequencies across the three types of words.

Why were first-fixation durations on compound words longer than first-fixation durations on suffixed and monomorphemic words? It appears unlikely that compound words' syllabic complexity, their phonological regularity, or the word frequency of their initial morpheme can account for increased first-fixation durations. The syllabic structure of compound words was less complex than the structure of control words, all compound words were phonologically regular, and the word initial constituent of compound words was particularly familiar; yet compound words received the longest first-fixation durations.

However, compound words also differed from the other two types of words in their spatial distribution of meaningdefining information. Compound words contained informative word endings (the ending constituent formed the morphological "head"); suffixed words contained informative beginnings. In monomorphemic words, the beginning segment may also be of particular importance for the accessing of lexical information (Inhoff \& Tousman, 1990). Consequently, first-fixation durations on compound words could have been longer because the readers sought meaningdefining information from an atypical intraword location. Yet this initial emphasis on the word ending could have provided benefits during refixations, leveling differences between the three word types when gaze durations were analyzed.

\section{EXPERIMENT 2 On-Line and Delayed Naming Tasks}

If effects of lexical analyses on first-fixation durations during sentence generalized to on-line naming, as argued by Pollatsek et al. (1992), then on-line naming of compound words should require longer latencies than should the naming of suffixed and control words. Differences in the re- 
sults of reading and on-line naming tasks, if evident, should be attributed to confounding effects of speech planning in the naming task (McRae et al., 1992; Inhoff \& Topolski, 1994b). Experiment 2 used the targets of Experiment 1 in an on-line naming task to determine whether morphemerelated effects generalize across reading and naming tasks. To assess the potential contribution of speech-planning demands, Experiment 2 also included a delayed naming task in which the naming cue was presented after a target was identified.

\section{Method}

Subjects. Twenty-six undergraduate students of the State University of New York at Binghamton participated in the experiment for experimental course credit. All subjects were native speakers of English and were naive about the purpose of the experiment. None had participated in Experiment 1.

Apparatus. Stimuli were presented via a CRT in light gray on a black background, and articulatory responses were recorded via a Gerbrands voice-key system. CRT and voice-key system were interfaced with a microcomputer that was used to control the timing of the visual display and to record naming latencies (between the onset of the naming cue and voice-key activation) to the nearest $1 \mathrm{msec}$. Head and chin position were not restrained in order to ensure that articulatory responses were not impeded by external devices, but the CRT was positioned to yield a typical eye-stimulus distance of $80 \mathrm{~cm}$. At this distance, each character subtended approximately $0.45^{\circ}$ of visual angle horizontally and $0.5^{\circ}$ vertically.

Stimuli. The 45 target words used in Experiment 1 were used in Experiment 2. In addition, 15 catch trials were added to diagnose naming strategies in the delayed naming task. In the on-line naming task, catch trials showed a string of homogeneous characters (e.g., $b b b b b b b b b$ or $k k k k k k k k k$ ) after fixation-marker offset. Catch trials were perceptually distinct and were easy to distinguish from target trials. In the delayed-naming task, a nine-letter filler word was visible for $500 \mathrm{msec}$ after the fixation-marker offset. Five compound, suffixed, and monomorphemic filler words were used. Filler-word presentation was immediately followed by the presentation of a homogeneous string of catch characters.

Procedure. The participants were tested individually in the online and delayed naming tasks. Each trial began with the presentation of a fixation marker at the screen center for $500 \mathrm{msec}$, followed by a 100-msec blank interval. In the on-line naming task, a to-be-named target or a letter string was presented, with each stimulus centered around the previously visible fixation marker. The participants were asked to name a word upon its presentation as fast and accurately as possible and to remain silent when a string of letters was presented. The target word was visible until the voice key was activated. Silent catch trials were terminated automatically after an interval of $3 \mathrm{sec}$. All naming latencies were measured from the onset of the target- word presentation. After a short break, the on-line naming task was followed by a delayed naming task.

In this task, offset of the fixation was followed by the initial presentation of a target or a filler word; at this time, each word was shown in parentheses for $500 \mathrm{msec}$-for example, (blueberry). The participants were instructed to identify, but not to name, the visible word while it was shown in parentheses. On target trials, the parentheses were removed after the $500-\mathrm{msec}$ interval, with the removal serving as naming cue. Since all targets had been read before and were visible for $500 \mathrm{msec}$, targets should have been fully recognized during the initial 500-msec presentation interval (target-viewing durations in Experiment 1 were considerably shorter than $500 \mathrm{msec}$ ). On catch trials, filler words were replaced with a string of homogeneous "catch" letters (shown without parentheses), and the participants were asked to remain silent. Delayed naming latencies measured the interval between the onset of the naming cue and voice-key activation. Silent catch trials were terminated after a 3-sec interval.

Data analyses. Trials with target presentations were analyzed. Responses to targets with extremely short ( $\leq 150 \mathrm{msec}$, on-line naming only) or extremely long $(\geq 1,500 \mathrm{msec})$ latencies were discarded. Extremely brief latencies were generally due to extraneous noises (moving a chair, coughing); extremely long latencies were rare and generally occurred only on the first trial, when some subjects were unprepared for the initial stimulus presentation.

In the delayed naming task, the participants could identify the visible word and name it without waiting for the onset of the naming cue. Since recognition and speech programming will generally exceed $500 \mathrm{msec}$ (McRae et al., 1990), an on-line naming strategy in delayed naming would yield shorter naming latencies but similar data patterns in the two tasks. To identify the use of an on-line naming strategy in the delayed naming task, the participants were asked to signal instances in which word namings were executed in response to word onset rather than to naming-cue onset. In addition, performance on the 15 catch trials was used to diagnose the use of an online naming strategy. On these trials, on-line naming should yield a large number of filler-word namings, since the $500-\mathrm{msec}$ presentation of a filler word was immediately followed by a "silent" letter string. Six of the 26 participants named filler words on $33 \%$ or more of the catch trials. They were excluded from analyses.

Three types of errors were discriminated: accidental activations of the voice key, incorrect articulations, and premature namings (delayed naming only). Accidental activations of the voice key occurred on less than $1 \%$ of the trials in the on-line and delayed naming tasks. These trials were excluded from further consideration. The remaining errors and naming latencies on error-free trials were statistically analyzed. Results from the two tasks are presented separately.

\section{Results: On-Line Naming}

Error rates. Inaccurate articulations (see Table 2) were rare, occurring on less than $1 \%$ of the trials. Virtually all errors were due to the misarticulation of the control word

Table 2

Target Naming Latencies (in Milliseconds) and Error Rates (\%) as a Function of Word Type in the On-Line and Delayed Naming Tasks

\begin{tabular}{|c|c|c|c|c|c|c|c|c|c|c|}
\hline \multirow[b]{4}{*}{ Word Type } & & & & & \multicolumn{6}{|c|}{ Delayed Naming } \\
\hline & \multicolumn{4}{|c|}{ On-Line Naming } & \multicolumn{4}{|c|}{ Error Rates } & \multirow{2}{*}{\multicolumn{2}{|c|}{ Latencies }} \\
\hline & \multicolumn{2}{|c|}{ Speech Errors } & \multicolumn{2}{|c|}{ Latencies } & \multicolumn{2}{|c|}{ Premature Naming } & \multicolumn{2}{|c|}{ Speech Errors } & & \\
\hline & $\%$ & $S D$ & $M$ & $S D$ & $\%$ & $S D$ & $\%$ & $S D$ & $M$ & $S D$ \\
\hline Compound & 0.3 & 1.3 & 544 & 90 & 1.3 & 2.7 & 0 & & 434 & 75 \\
\hline Suffixed & 0.5 & 1.8 & 582 & 107 & 3.3 & 5.9 & 0.3 & 1.5 & 457 & 81 \\
\hline Monomorphemic & 2.3 & 3.3 & 596 & 105 & 4.0 & 5.9 & 3.3 & 3.4 & 433 & 75 \\
\hline
\end{tabular}

Note $-M$, mean. $S D$, standard deviation. 
precipice, resulting in a significant effect of word type $\left[F 1(2,50)=6.89, M S_{\mathrm{e}}=5.9, p<.005\right] .{ }^{4}$ Paired comparisons revealed reliably more errors on control words than on compound and suffixed words $[t 1(25)=3.14, p<.005$, and $t 1(25)=2.54, p<.025$, respectively].

Naming latencies. Naming latencies, as a function of word type, are also shown in Table 2.

Naming latencies were considerably shorter for compound words $(544 \mathrm{msec})$ than for suffixed and control words (582 and $596 \mathrm{msec}$, respectively) $[F 1(2,50)=18.83$, $M S_{\mathrm{e}}=1,003, p<.001 ; F 2(2,28)=5.33, M S_{\mathrm{e}}=2,104$, $p<.025]$. Additional paired comparisons showed that naming latencies were significantly shorter for compound words than for suffixed words $[t 1(25)=4.81 ; t 2(14)=$ $2.29]$ and for control words $[t 1(25)=6.64 ; t 2(14)=3.79]$ (all $p \mathrm{~s}<.05$ ). The difference between suffixed and control words was not reliable (all $p s>.2$ ).

Supplementary analyses. As noted previously, compound, suffixed, and control words differed on a number of lexical stimulus characteristics, all of which could have affected on-line naming latencies. Jared and Seidenberg (1990) showed that on-line naming latencies were a function of syllabic complexity, with shorter latencies for monosyllabic words than for quattrosyllabic words. Naming latencies are also shorter for phonologically regular (monosyllabic) words than for irregular words (e.g., Inhoff \& Topolski, 1994b). Both characteristics could have increased control-word naming latencies. Conversely, naming latencies of compound words may have been relatively short, because their initial word/morpheme was particularly familiar. Finally, examination of word initial phonemes indicated that suffixed words contained a disproportionately large number of "slow" onsets. Specifically, Balota and Chumbley's (1985) and Connine, Titone, and Wang's (1993) subanalyses showed that word initial phonemes with a relatively low amplitude onset (e.g., $s, f$, or $h$ ) are slower in activating the voice key than are phonemes with a relatively high amplitude onset (e.g., $p, d$, or $g$ ). This could have increased the difference between compound and suffixed words and decreased the difference between control and suffixed words.

A supplementary multiple linear regression analysis was executed to examine the effects of these potential confounds on naming latencies. Five predictors were used, consisting of the number of syllables ( 2 or 3 ), phonological regularity $(1=$ regular, $2=$ irregular $)$, the word frequency of the initial morpheme constituent (zero values for control words), the amplitude onset of the initial phoneme $(1=$ slow, $2=$ fast $)$, and the number of viable morphemic access codes $(1=$ control words, $2=$ suffixed words, $3=$ compound words). Following Lorch and Myers (1990), the predictors were entered simultaneously to obtain the corresponding regression coefficients. The data of each participant were analyzed separately. This was followed by a single-group $t$ test, which was applied to each of the five sets of coefficient values.

The number of morphemic access codes was by far the most potent predictor, accounting for $19 \%$ of response time variability $[t(24)=7.50, p<.001]$, indicating that effects of morphemic word structure persisted even when effects of potential confounds were removed. However, the familiarity of the word initial morpheme and the "speed" of the word initial phoneme also predicted on-line naming latencies, each accounting for $6 \%$ of the variance. Specifically, naming latencies decreased with the word frequency of the initial morpheme $[t(24)=2.30, p<.05]$ and the speed of the initial phoneme $[t(24)=2.65, p<.01]$.

Effects of syllable complexity and phonological regularity were in the anticipated directions, with longer naming latencies for words with three syllables and with irregular phonology, but the effects failed to approach significance $[t(24)=1.37$, and $t(24)=1.39]$ (both $p s>$ .1). This appears to disagree with Jared and Seidenberg's (1990) results, which showed a relatively robust $(34 \mathrm{msec})$ effect of syllable structure for low-frequency words. Effects of phonological regularity were negligible, presumably because phonological irregularities generally applied to ending syllables. Tousman and Inhoff (1992) showed that phonologically misleading word initial syllable primes (e.g., gla of glacial) interfered with subsequent word naming, whereas phonologically misleading ending syllable primes (e.g., ive of naive) did not.

\section{Discussion}

On-line naming latencies revealed a robust effect of word structure with substantially shorter naming latencies for compound words than for suffixed and control words. Effects of word structure remained robust, even when effects of beginning-subword familiarity, phonological regularity, and syllable structure were removed. Naming latencies were also slightly $(14 \mathrm{msec})$ shorter for suffixed words than for control words. However, the small difference was not reliable, possibly because suffixed words contained a disproportionately large number of slow word initial phonemes.

The pattern of effects in Experiment 2 is thus consistent with the view that both morphemes of compound words (and full word forms) are used in the word recognition process. Since, according to this view, compound words contained the largest number of access codes, their recognition was particularly effective. However, this account conflicts with the results of Experiment 1, which showed relatively long first-fixation durations on compound words.

Instead of being determined by lexical access processes, on-line naming latencies could be determined by the ease of speech programming. Postlexical specification of articulatory codes could have been more effective when compound words were named than when suffixed and control words were named. Specifically, the speech planning for compound words' second morpheme constituent may have been independent of the speech planning for the initial morpheme. In contrast to this, the planning of suffix pronunciations may have had to follow the prior specification of root articulations. Similarly, speech planning may have been strictly sequential (and slow) when the articulatory code of control words was determined. The speech-planning hypothesis can also account for effects of word initial morpheme/word frequencies on naming latencies, since the 
speech programming of high-frequency words may be more effective than the speech planning of low-frequency words (McRae et al., 1990).

\section{Results: Delayed Naming}

Error rates. Errors occurred on slightly more than 4\% of the delayed naming task trials. Premature naming errors and misarticulations, as a function of word type, are shown in Table 2. A 2 (error type) $\times 3$ (target type) ANOVA revealed a marginally significant effect of error type $[F 1(1,19)$ $\left.=4.30, M S_{\mathrm{e}}=19, p<.06\right]$, with slightly more premature namings than misarticulations, and a highly robust effect of word type $\left[F 1(1,19)=9.15, M S_{\mathrm{e}}=10, p<.001\right]$. Again, the word precipice accounted for the vast majority of misarticulations. The interaction of word type and error type was negligible $(F<1)$. Paired comparisons revealed a significantly higher error rate when control words were named than when compound and suffixed words were named $[t 1(19)=3.94, p<.001$, and $t 1(19)=2.46, p<.025$, respectively]. The difference between compound and suffixed words was negligible $(t<1)$.

Naming latencies. Delayed naming latencies (see Table 2) were also a function of the morphological composition of the to-be-named word. The effect was robust in the $F 1$ analysis $\left[F 1(2,38)=4.13, M S_{\mathrm{e}}=945, p<\right.$ $.025]$ but did not approach significance in the $F 2$ analysis $\left[F 2(2,28)=1.31, M S_{\mathrm{e}}=1,237, p>.28\right]$. Paired comparisons, applied to the $F 1$ data, revealed significantly longer delayed naming latencies for suffixed words than for compound and control words $[t 1(19)=3.10, p<.01$, and $t 2(14)=2.39, p<.05$, respectively].

Supplementary analyses. Syllable complexity, phonological regularity, the lexical familiarity of the word initial segment, the speed of the word initial phoneme, and the number of lexical access codes were again used to predict the naming latencies of each participant. The word frequency of the word initial segment and of the speed of the word initial phoneme accounted for $6 \%$ and $7 \%$, respectively, of the variability in the data. Single group $t$ tests showed that these contributions were significant $[t(19)=$ $1.72, p<.05$, and $t(19)=1.80, p<.05$, respectively]. Presumably, "fast" word initial phonemes yielded shorter naming latencies, because their high-amplitude word onsets led to faster voice-key activations, and speech planning was more effective when the beginning word segment was lexically familiar. Syllable complexity, phonological regularity, and the number of lexical access codes accounted for $0 \%, 2 \%$, and $2 \%$, respectively, of the variability in the data; none of these contributions was significant (all $t s<1$ ).

\section{Discussion}

Similar to the on-line naming task, most errors were made during the naming of the control word precipice. Speech errors in the on-line and delayed naming tasks thus appear to be independent of the recognition processes and may be determined by the success with which a speech program is implemented. Similar to the results of the on-line naming task, delayed naming latencies were also shorter for compound words than for suffixed words, and latencies decreased when the lexical familiarity of the beginning word segment increased, even though a word was visible for $500 \mathrm{msec}$ prior to the onset of the naming cue.

Interpretation of the delayed naming latencies is, however, not straightforward. Similarities between on-line and delayed naming latencies suggest that naming latencies were a function of speech-planning demands in both tasks. Several other considerations suggest, however, that on-line naming latencies were also sensitive to word recognition processes.

First, the difference in naming latencies between compound and suffixed words was substantially larger in the on-line naming task than in the delayed naming task. Second, effects of morphology, which were robust across items and participants in the on-line naming task, were no longer reliable cross items in the delayed naming task. Third, the large and robust difference between compound and control words in the on-line naming task was completely absent in the delayed naming task. Finally, supplementary regression analyses of delayed naming latencies indicated that longer naming latencies for suffixed words were probably due to the relatively large proportion of "slow" word initial phonemes.

\section{GENERAL DISCUSSION}

The main results of the present study revealed that firstfixation duration was $26 \mathrm{msec}$ longer when compound words were read than when monomorphemic control words were read; yet, on-line naming latency for compound words was $52 \mathrm{msec}$ shorter than that for monomorphemic controls. In contrast to Pollatsek et al.'s (1992) view, on-line naming latencies and first-fixation durations during reading thus yielded an opposing pattern of effects.

Perhaps on-line naming and first-fixation durations differed in the present study because naming responses were particularly sensitive to speech-planning demands. The results of the delayed naming task of Experiment 2 rejected this possibility. Delayed naming latencies for compound and control words were virtually identical, indicating that postlexical speech planning did not selectively benefit the naming of compound words.

Alternatively, on-line naming latencies and first-fixation durations may have differed because the two tasks were not equated for the visibility of target words. During sentence reading, a target word was visible in the parafovea prior to its fixation. A considerable number of studies have shown that parafoveal preview has a profound effect on subsequent word-viewing durations (see Rayner \& Pollatsek, 1989 , for a review of parafoveal preview benefits). If use of parafoveal information was a function of the previewed target's morphemic structure, then morpheme-related effects could take one form when parafoveal preview was available, as occurred in the reading task, and a different form when no preview was available, as occurred in the on-line naming task. It is unclear, however, why and how parafoveal preview would reverse morpheme-related ef- 
fects. Furthermore, parafoveally available previews of the initial morpheme of compound words are not used for the specification of morphemic structure (Inhoff, 1989a).

Perhaps the use of morphemic information was affected by the availability of sentence contexts, which were available in the reading task but not in the on-line naming task. We cannot rule out this possibility. However, we know of no empirical study that has shown a context-induced reversal of morpheme-related effects. Furthermore, it is, again, unclear why and how such a reversal of effects would occur. The view that context reversed morphology-related effects across tasks is also undermined by the results of the norming study in Experiment 1 , which indicated that all three target types were equally constrained by preceding sentence contexts.

The conflicting results of the reading and on-line naming studies can be reconciled, however, if it is assumed that the two tasks are sensitive to functionally distinct phases of the meaning-specification process. On-line naming may be initiated before the full word is recognized. This could benefit compound words whose initial segment is represented in the lexicon. This view is, however, difficult to reconcile with related findings. On-line naming is sensitive to the fast, automatic activation of word meanings (Joordens \& Besner, 1992), which makes it plausible to assume that both lexical constituents of compound words were activated. Consonant with this view, Andrews's (1986) and Lima and Pollatsek's (1983) lexical decision task results showed that both lexical constituents of compound nonwords determined classification latencies. Consequently, the compound-word superiority in the naming task appears to be linked to the more effective activation of both meaning-defining constituents. During the automatic phase of lexical activation, both constituents of a compound word may contribute to lexical activation, irrespective of the constituents' intraword location. Their joint contribution to lexical activation could account for relatively fast on-line naming latencies.

Lexical activation and meaning assignment may proceed differently in the reading task. Here, sentence comprehension requires the availability of a fixed, conventional word meaning. During its computation, the contribution of the two constituents of compound words can no longer be considered independent of their intraword location. Instead, the meaning associated with the initial constituent must be subordinated to the meaning of the ending constituent. The atypical distribution of meaning-defining information in compound words could thus hamper the derivation of conventional word meanings, accounting for increased firstfixation durations. Yet, costs during the initial fixation of a compound word were offset by savings during target refixations, leveling the differences between the three types of target words when the gaze data were computed in Experiment 1.

Reading and on-line naming tasks revealed, however, similar performances for suffixed and control words. On the one hand, this finding is congruent with Bergman et al.'s (1988) findings. As noted before, lexical decision times in Bergman et al.'s study were equivalent for affixed and monomorphemic words. On the other hand, the lack of a suffix-related effect disagrees with several priming studies (Feldman \& Bentin, 1994; Fowler et al., 1985), and the small 14-msec difference between suffixed and control words in the on-line naming task could have been underestimated by the "slowness" of suffixed words' initial phoneme.

These results also have methodological and theoretical implications. The two most frequently used word-viewing measures, first-fixation durations and gaze durations, yielded different patterns of effects, with first-fixation durations being longer when compound words were fixated than when control words were fixated and gaze durations being equivalent for the two types of words. Furthermore, neither word-viewing measure corresponded to on-line naming latencies, which were relatively short when compound words were viewed. We propose that discrepancies between measures are informative, since each may be sensitive to a different phase of the compound-word recognition process. In particular, naming latencies appear to index the initial phase of lexical activation, whereas firstfixation durations and gaze durations appear to index the assignment of conventional word meaning.

\section{REFERENCES}

ANDREWs, S. (1986). Morphological influences on lexical access: Lexical or nonlexical effects. Journal of Memory \& Language, 25, 726-740.

Balota, D. A., \& Chumbley, J. I. (1984). Are lexical decisions a good measure of lexical access? The role of word frequency in the neglected decision stage. Journal of Experimental Psychology: Human Perception \& Performance, 10, 340-357.

Balota, D. A., \& Chumbley, J. I. (1985). The locus of word-frequency effects in the pronunciation task: Lexical access and/or production frequency? Journal of Verbal Learning \& Verbal Behavior, 24, 89106 .

BALUCH, B., \& BESNER, D. (1991). Visual word recognition: Evidence for strategic control of lexical and nonlexical routines in oral reading. Journal of Experimental Psychology: Learning, Memory, \& Cognition, 17, 644-652.

Beauvillain, P. C. C., \& Segui, J. (1989). On the presentation and processing of prefixed and suffixed derived words: A differential frequency effect. Journal of Memory \& Language, 28, 1-13.

Bergman, M. W., Hudson, P. T. W., \& Eling, P. A. T. M. (1988). How simple complex words can be: Morphological processing and word representations. Quarterly Journal of Experimental Psychology, 40A, $41-72$.

Carr, T., \& Pollatsek, A. (1985). Recognizing printed words: A look at current models. In D. Besner, T. G. Waller, \& G. E. MacKinnon (Eds.), Reading research: Advances in theory and practice (Vol. 5, pp. 2-73). Orlando, FL: Academic Press.

Connine, C., Titone, D., \& Wang, J. (1993). Auditory word recognition: Extrinsic and intrinsic effects of word frequency. Journal of Experimental Psychology: Learning, Memory, \& Cognition, 19, $81-94$.

CosletT, H. B., \& SAFFRAN, E. M. (1989). Evidence for preserved reading in pure alexia. Brain, 112, 327-359.

DELL, G.S. (1986). A spreading activation theory of retrieval in sentence production. Psychological Review, 93, 283-321.

FELDMAN, L. B. (1994). Beyond orthography and phonology: Differences between inflections and derivations. Journal of Memory \& Language, 33, 442-470.

Feldman, L. B., \& Bentin, S. (1994). Morphological analysis of disrupted morphemes: Evidence from Hebrew. Quarterly Journal of Experimental Psychology, 47A, 407-435.

Fowler, C. A., NAPPS, S. E., \& FELDMAN, L. (1985). Relations among regular and irregular morphologically related words in the lexicon as revealed by repetition priming. Memory \& Cognition, 13, 241-255. Gielen, I., Brysbaert, M., \& Dhondt, A. (1991). The syllable-length 
effect in number processing is task-dependent. Perception \& Psychophysics, 50, 449-458.

INHOFF, A. W. (1984). Two stages of word processing during eye fixations in the reading of prose. Journal of Verbal Learning \& Verbal Behavior, 23, 612-624.

INHOFF, A. W. (1987). Parafoveal word perception during eye fixations in reading: Effects of visual salience and word structure. In M. Coltheart (Ed.), Attention and performance XII: The psychology of reading (pp. 403-420). Hillsdale, NJ: Erlbaum.

INHOFF, A. W. (1989a). Lexical access during eye fixations in reading: Are word access codes used to integrate lexical information across interword fixations? Journal of Memory \& Language, 28, 444-461.

INHOFF, A. W. (1989b). Parafoveal processing of words and saccade computation during eye fixations in reading. Journal of Experimental Psychology: Human Perception \& Performance, 15, 544-555.

INHOFF, A. W., \& RAYNER, K. (1986). Parafoveal word processing during eye fixations in reading: Effects of word frequency. Perception \& Psychophysics, 40, 431-439.

INHOFF, A. W., \& TOPOLSKI, R. (1994a). Seeing morphemes: Loss of visibility during the retinal stabilization of compound and pseudocompound words. Journal of Experimental Psychology: Human Perception \& Performance, 20, 840-853.

INHOFF, A. W., \& TOPOLSKI, R. (1994b). Use of phonological codes during eye fixations in reading and in on-line and delayed naming tasks. Journal of Memory \& Language, 33, 689-713.

INHOFF, A. W., \& Tousman, S. (1990). Lexical priming from partial word previews. Journal of Experimental Psychology: Learning, Memory, \& Cognition, 16, 825-836.

JARED, D., \& SeIdenberG, M. (1990). Naming multisyllabic words. Journal of Experimental Psychology: Human Perception \& Performance, 16, 92-105.

JoORDENS, S., \& BESNER, D. (1992). Priming effects that span an intervening unrelated word: Implications for models of memory representation and retrieval. Journal of Experimental Psychology: Learning, Memory, \& Cognition, 18, 483-491.

Just, M., \& CARPENTER, P. A. (1990). A theory of reading: From eye fixations to comprehension. Psychological Review, 87, 329-354.

KuČERA, H., \& FRANCIS, W. N. (1967). Computational analysis of presentday American English. Providence, RI: Brown University Press.

LIMA, S. D., \& INHOFF, A. W. (1985). Lexical access during eye fixations in reading: Effects of word-initial letter sequence. Journal of Experimental Psychology: Human Perception \& Performance, 11, 272-285.

Lima, S. D., \& Pollatsek, A. (1983). Lexical access via an orthographic code? The Basic Orthographic Syllabic Structure (BOSS) reconsidered. Journal of Verbal Learning \& Verbal Behavior, 22, 310332.

LORCH, R. F., \& MYERS, J. L. (1990). Regression analyses of repeated measures data in cognitive research. Journal of Experimental Psychology: Learning, Memory, \& Cognition, 16, 149-157.

MCConkie, G. W., KeRR, P. W., Redix, M. D., \& Zola, D. (1988). Eye movement control during reading: 1 . The location of the initial fixation in words. Vision Research, 28, 1107-1118.

MCRae, K., JaRed, D., \& SeidenberG, M. (1990). On the role of frequency and lexical access in word naming. Journal of Memory \& Language, 29, 43-65.

Monsell, S., Doyle, M. C., \& Haggard, P. N. (1989). Effects of frequency on visual word recognition tasks: Where are they? Journal of Experimental Psychology: General, 118, 43-71.

Monsell, S., Patterson, K. E., Graham, A., Hughes, C. H., \& MilROY, R. (1992). Lexical and sublexical translation of spelling to sound: Strategic anticipation of lexical status. Journal of Experimental Psychology: Learning, Memory, \& Cognition, 18, 452-467.

O'ReGaN, J. K. (1990). Eye movements and reading. In E. Kowler (Ed.), Eye movements and their role in visual and cognitive processes: Reviews of oculomotor research (pp. 395-454). Amsterdam: Elsevier.

PAAP, K. R., \& NOEL, R. W. (1991). Dual route models of print to sound: Still a good horse race. Psychological Research, 53, 13-24.

Pollatsek, A., Lesch, M., Morris, R., \& Rayner, K. (1992). Phono- logical codes are used in integrating information across saccades in word identification and reading. Journal of Experimental Psychology: Human Perception \& Performance, 18, 148-162.

PrinzMETAL, W. (1990). Neon colors illuminate reading units. Journal of Experimental Psychology: Human Perception \& Performance, 16, 584-597.

Prinzmetal, W., Hoffman, H., \& Vest, K. (1991). Automatic processes in word perception: An analysis from illusory conjunction. Journal of Experimental Psychology: Human Perception \& Performance, 17, 902-923.

RAPP, B. C. (1992). The nature of sublexical orthographic organization: The bigram trough hypothesis examined. Journal of Memory \& Language, 31, 33-54.

RAYNER, K. (1979). Eye guidance in reading: Fixation location within words. Perception, 8, 21-30.

RAYNER, K., \& DUFFY, S. A. (1986). Lexical complexity and fixation times in reading: Effects of word frequency, verb complexity, and lexical ambiguity. Memory \& Cognition, 14, 191-201.

RaYNeR, K., \& PollatSeK, A. (1987). Eye movements in reading: A tutorial review. In M. Coltheart (Ed.), Attention and performance XII: The psychology of reading (pp. 327-363). Hillsdale, NJ: Erlbaum.

Rayner, K., \& Pollatsek, A. (1989). The psychology of reading. Englewood Cliffs, NJ: Prentice Hall.

SANDRA, D. (1990). On the representation and processing of compound words: Automatic access to constituent morphemes does not occur. Quarterly Journal of Experimental Psychology, 42A, 529-567.

SEIDENBERG, M. S. (1987). Sublexical structure in visual word recognition: Access units or orthographic redundancy? In M. Coltheart (Ed.), Attention and performance XII: The psychology of reading (pp. 245264). Hillsdale, NJ: Erlbaum

Seidenberg, M. S., Waters, G. S., SAnders, M., \& Langer, P. (1984) Pre- and postlexical loci of contextual effects on word recognition. Memory \& Cognition, 12, 315-328

Solso, R. L., \& JUEL, C. L. (1980). Positional frequency and versatility of bigrams for two- through nine-letter English words. Behavior Research Methods \& Instrumentation, 12, 297-343.

TAFT, M. (1985). The decoding of words in lexical access: A review of the morphographic approach. In D. Besner, T. G. Waller, \& G. E. MacKinnon (Eds.), Reading research: Advances in theory and practice (Vol. 5, pp. 83-124). Orlando, FL: Academic Press.

TAFT, M., \& ForSTER, K. I. (1976). Lexical storage and retrieval of polymorphemic and polysyllabic words. Journal of Verbal Learning \& Verbal Behavior, 15, 607-620.

Tousman, S., \& INHOFF, A. W. (1992). Phonology in multisyllabic word recognition. Journal of Psycholinguistic Research, 21, 525-544.

Vitu, F., O'Regan, J. K., INHOFF, A. W., \& ToPOLSKI, R. (1995). Mindless reading: Eye-movement characteristics are similar in scanning letter strings and reading texts. Perception \& Psychophysics, 57, 352-364.

\section{NOTES}

1. This post hoc classification yielded an uneven number of items per cell, which made computation of $F 2$ values no longer possible.

2 . The subanalyses also revealed robust main effects of fixation location. First fixations were longer when a target's center/ending position was fixated than when a beginning position was fixated $[F 1(1,24)=$ $\left.48.40, M S_{\mathrm{e}}=1,787, p<.001\right]$. Gaze durations showed the reversed position effect, with substantially longer gazes after target-beginning fixations $\left[F 1(1,24)=80.28, M S_{\mathrm{e}}=5,578, p<.001\right]$. Target refixations occurred more often when a target-beginning location had been fixated (see Figure 1), accounting for the reversal of fixation location effects in the two sets of viewing duration data.

3. Refixations were uncommon in the majority of readers but were quite common in some readers. Refixation rates were thus somewhat lower when values were averaged across readers than when the raw data were used (as shown in Figure 1).

4. A large number of items did not yield any incorrect naming, making computation of $F 2$ values uninformative. 
APPENDIX

Compound, Suffixed, and Monomorphemic Words Used in Experiments 1-2

\begin{tabular}{|c|c|}
\hline Word & Frequency \\
\hline \multicolumn{2}{|c|}{ Compound Words } \\
\hline blueberry & 1 \\
\hline caretaker & 1 \\
\hline copyright & 1 \\
\hline evergreen & 1 \\
\hline fairytale & 1 \\
\hline flowerpot & 2 \\
\hline gunpowder & 2 \\
\hline homegrown & 2 \\
\hline middleman & 1 \\
\hline nightmare & 10 \\
\hline overthrow & 5 \\
\hline sandpaper & 1 \\
\hline timetable & 4 \\
\hline turntable & 1 \\
\hline waterfall & 2 \\
\hline \multicolumn{2}{|c|}{ Suffixed Words } \\
\hline ceaseless & 3 \\
\hline falsehood & 2 \\
\hline harshness & 1 \\
\hline heartless & 1 \\
\hline northward & 5 \\
\hline plumpness & 4 \\
\hline quenching & 1 \\
\hline roundness & 1 \\
\hline sainthood & 1 \\
\hline shrinkage & 3 \\
\hline smallness & 2 \\
\hline soundness & 1 \\
\hline sparkling & 5 \\
\hline strolling & 4 \\
\hline thankless & 1 \\
\hline \multicolumn{2}{|c|}{ Monomorphemic Words } \\
\hline arthritis & 3 \\
\hline boomerang & 1 \\
\hline carpenter & 6 \\
\hline catalogue & 3 \\
\hline cathedral & 8 \\
\hline champagne & 13 \\
\hline chronicle & 5 \\
\hline guarantee & 10 \\
\hline hibernate & 2 \\
\hline marmalade & 1 \\
\hline porcelain & 2 \\
\hline pragmatic & 4 \\
\hline precipice & 1 \\
\hline scoundrel & 2 \\
\hline sophomore & 5 \\
\hline
\end{tabular}

(Manuscript received January 25, 1995; revision accepted for publication May 17, 1995.) 